\title{
A sphere of resonance for networked learning in the 'non-places' of our universities
}

\section{Sarah Hayes}

Centre for Learning, Innovation and Professional Practice, Aston University, UK

\begin{abstract}
The logic of 'time' in modern capitalist society appears to be a fixed concept. Time dictates human activity with a regularity, which as long ago as 1944, George Woodcock referred to as The Tyranny of the Clock. Seventy years on, Hartmut Rosa suggests humans no longer maintain speed to achieve something new, but simply to preserve the status quo, in a 'social acceleration' that is lethal to democracy. Political engagement takes time we no longer have, as we rush between our virtual spaces and 'non-places' of higher education. I suggest it is time to confront the conspirators that, in partnership with the clock, accelerate our social engagements with technology in the context of learning. Through Critical Discourse Analysis I reveal an alarming situation if we do not. With reference to Bauman's Liquid Modernity, I observe a 'lightness' in policy texts where humans have been 'liquified' Separating people from their own labour with technology in policy maintains the flow of speed a neoliberal economy demands. I suggest a new 'solidity' of human presence is required as we write about networked learning. 'Writing ourselves back in' requires a commitment to 'be there' in policy and provide arguments that decelerate the tyranny of time. I am, though, ever-mindful that social acceleration is also of our own making, and there is every possibility that we actually enjoy it.
\end{abstract}

\section{Keywords}

Time, policy, Critical Discourse Analysis, networked learning

\section{Introduction}

In 1944, George Woodcock (1912-1995) the Canadian anarchist, poet, literary critic and historian wrote The Tyranny of the Clock. Quoting Lewis Mumford, he described the clock as the first automatic machine to attain any importance in people's lives. Once sunrise, sunset or trickling sand provided a craftsperson with inexact indications of the passing of time. Human labour, and a person's interaction with their tools, was not measured through 
precise, time-delimited mechanisms, but experienced individually. Physical work accomplished was a measure in itself, our material engagement clearly indicating what had been achieved, rather than simply the passing of a length of time. In modern society, the clock (now existing in many physical and virtual forms) dictates human movements and inhibits our actions more potently than any individual exploiter or machine (Woodcock, 1944). In capitalism, an emphasis on quantity, in exchange for human labour with technologies, rather than quality, has brought about a slavish dependence on mechanical time, as a social norm where people speed up even their responses to their own education.

Humans seem to have turned time into a commodity measured by the spaces of a clock dial, 'to be bought and sold like soap or sultanas' (Woodcock, 1944). Woodcock's observations on tyranny in industrial society paint a dismal view, where the tired worker has become a 'clock-watcher' who escapes the monotony and regulation of work only to 'kill time' in other mechanised forms of enjoyment (Woodcock, 1944). Writing at a time when industrial productivity was still effectively regulated through Fordism, we might wonder whether Woodcock's observations on the clock still hold relevance for our networked lives in a digital society and indeed for networked forms of learning in higher education. We have since seen post-industrial countries deregulate economic life, reduce the role of the state and open trade to global market flows (Cohen and Kennedy, 2013: 72). In this new neoliberal form of the capitalist economy we now dwell in spaces of 'networked individualism' that are no longer tied to workplaces, universities or home-time space boundaries (Wellman, 2001). Yet Sherry Turkle, in her book Alone Together, argues that technology still proposes itself as 'the architect of our intimacies'. Overwhelmed by the volume of tasks and sheer velocity in our lives, we turn to technology to help us find time as we resort to texting each other instead of meeting (Turkle, 2011). Therefore, despite economic, technological and social transformations, the spaces of a clock continue to regulate our human spaces via our mobile phones. Such changes have impact too on our gathering in physical places, for technological learning in higher education.

Despite new communication possibilities, our experience of time still appears to be more decided and fixed than perhaps it should be. The clock still dictates the pace in a digital present that has replaced the industrial past, and the future comes next... Or does it? If we succumb too much to such a linear chronological order, as a form of historical determinism, we take the position that modern life (and indeed modern technology) should be emancipated from the 'dead hand' of its own history and politics (Bauman, 2000). Our contemporary social system begins to 'lose its capacity to retain its own past' (Jameson, 1992: 179). Connections to what has gone before appear to become severed. This is a dangerous position given technology is a distinctive feature of modernity (Marcuse, 1964). We may 'begin' from a deterministic assumption that technology, as a neutral tool, has enhanced learning (Bayne, 2014), but this is a problematic and unconsidered presumption, based on the expectation of an 'exchange value' for learning from technology (Hayes and Bartholomew, 2015).

Scholars in Science and Technology Studies (STS), such as Langdon Winner, argue our technologies are not neutral, but instead they contain sets of beliefs that are dialectical with the capitalist society we inhabit, for example that power should be centralised, good things unevenly allocated and people's lives open to surveillance and scrutiny (Winner, 1993: 288). We need to retain awareness of the values that constitute the items we use, as even now in higher education, we continue to subordinate technology, to further regulation and exploitation of our labour time. 


\section{Social acceleration}

Seventy years on from the writing of Woodcock, Hartmut Rosa, in his book called Social Acceleration (2013), makes the following two points that seem relevant in relation to university policy and human practices in the networked realm of educational technology. Firstly, Rosa suggests humans maintain speed simply to preserve the status quo (Rosa, 2013). In this article I ask: if we are maintaining speed in higher education primarily to preserve what we currently have, then should we not pause to take a closer look at what that 'status quo' is... if of course we have the time? We need to confront how we currently value time in academia before we can begin to imagine alternatives. Secondly, Rosa argues social acceleration is lethal to democracy, as a structural necessity to which humans must constantly re-orient themselves (Rosa, 2013). Democracy is time-consuming and humans no longer have time. Yet in education policy (and by association, educational technology policy), as a moral and political practice, we need to find time to prepare students to engage in critical thought on how higher education might contribute to the quality of democratic public life.

This involves furthering staff and student understanding of ways that technologies, in the broadest sense (texts, devices, spaces, organisations) may either contribute to a rapid dehumanisation of learning and academic life, or alternatively help us to rediscover why an interest in politics, time, technology and policy (together) matters for learning. Therefore, retaining perspective on what has gone before, as well as what is up ahead, is necessary to avoid mistaking technology as something neutral and separate from the politics that brought it into our lives and human learning contexts. We need to avoid the temptation to dissolve whatever 'solids' persist over time, looking towards a new more 'liquid modernity' (Bauman, 2000), seeking an ever-faster technological future, and accelerating our pace to get there. Compression of time and space has implications for how we experience the present (including our capacity for critical and reflexive learning), because we can now encompass places once thought to be at a considerable spatial, and therefore temporal, distance (Currie, 2007). Perhaps people now experience time differently in virtual environments. If so, could this lead to new, less linear conceptions of time and technology, where the present informs us on the past even as we anticipate possible futures? This is possible, unless there are conditions at play that constantly prevent this.

\section{Technological devices take many forms}

Taking the concerns of Woodcock and more recent ideas from Rosa (2013), I will firstly, examine some restrictions that social acceleration (and its conspirators in different structural forms) place on humans developing their own sphere of 'resonance' for networked learning. By 'conspirators' I refer to all manner of objects, practices, devices, texts, forms of organisation and even drugs and substances that I understand as technologies we may depend upon in order to manage our busy lives on less sleep and continue to postpone our tiredness. By 'resonance' I refer to a more positive reverberation, or sense of harmony, we experience through a connection with someone, or something. This leads to an interest and engagement that intrigues us to the extent that the spaces on a clock dial seem to lose their sense of urgency. By 'networked learning' I refer to the developing, and maintaining, of connections (over time) with people and all manner of 'things', for communicating in ways that support one another's learning (Jones and Steeples, 2002). 
Secondly, with reference to some examples from a Critical Discourse Analysis (CDA) that was undertaken to examine UK policy language about educational technology, I will demonstrate why our slavish dependence on mechanical time should not be viewed in isolation from other aspects of higher education within our political neoliberal economy. I raise concern about the way in which university policies for educational technology have been written in recent years. Configurations of statements about what 'the use of technology' can achieve, by their linear (often naïve) forms of expectation, serve to reinforce a culture of acceleration that values efficient technological processes over human academic labour. I link my observations about policy language with Bauman's concept in Liquid Modernity of 'melting the solids' (Bauman, 2000). I argue that particular textual formations in educational technology policy documents have enabled some rather limiting ideas about technology for learning to 'flow', 'spill' and 'flood' through universities, their 'lightness' or 'weightlessness' making it easier for them to travel at speed (Bauman, 2000).

Finally, through three concepts from Currie (2007), time-space compression, recontextualisation and archive fever, I explore how we might treat our emphasis on pressure from time rather differently, in an educational technology context and indeed the wider academy. These thoughts are intended to invite broader discussion on how policy and strategy for educational technology might be re-written to hold a resonance for those it concerns. A starting point would be to honestly and openly acknowledge our anxieties about time in respect of human technological learning. We might draw attention to the reality that it is still within the richness and limitations of human labour (not technology alone) that we support student learning. These academic activities are not constructed through linear, timelimited processes, but are organic, reflexive and dialectical with our other aspects of life.

\section{Conspirators with the clock}

There are now many new conspirators working with the clock that help to reinforce our enslavement to time, whether at work, study or at home. Indeed our online dwelling spaces are no longer separated, as they once were for the craftsperson, who knew (by indication from the sun) when it was time to 'down tools'. Furthermore, our virtual work is not so readily noticed as our physical labour once was. Virtual reality stays open for business day and night, never warning us (through sunrise, or sunset) that we might need to rest. Our information and communication technologies render it possible to be 'always on' (Gregg, 2013). Thus, our mobile devices and tablets help tighten a grip on us, as we check them with repetitive regularity during classes, meetings and even family dinners. Emails are textual tyrants that arrive indelibly stamped with a date and a time, awaiting response. Skype is there in the background reminding us of who else is online and timing our calls; thus, the clock is ticking (ticking us off, we may imagine) until we reply and set a new temporal challenge for each recipient of our own endless messages.... These observations have implications for understanding human learning in contemporary society, both on and offline, not as over a duration, but tightly packed into measurable 'lengths', rather like a set of processes that machines might conduct in sequence. It is rather less like the time required for developing human thought and related politics, connected with experience and material things, in different learning contexts, with compassion and emotion.

In the built world too, humans now encounter designs in the material culture of the city that hurry them along. Mike Davis described the destruction of public space, where modern urban renewal is so 'inhospitable' that it prevents people remaining anywhere long enough 
for structures to resonate with them. Public facilities are shrinking in a pattern that is replicated across cities (Davis, 1990: 226). For example, bus shelters now have minimal, cylindrical seats that support the briefest of pauses. Security cameras time how long we spend looking in the window of a store, or walking along a street. We find that within institutions there are no longer staffrooms available for informal conversations. Who would honestly have time to meet in them anyway, except to make a coffee and hastily return to our digital labour? Similarly, the lecture theatres in universities once designed for mass gatherings are now sparsely populated, as students elect to attend infrequently and instead connect through devices remotely. There is a sense of loss though too of an 'event' that is not so easily reconstituted online. The commitment to 'be there' (to be physically present) and share a resonance with other humans is ebbing away in many parts of life. This is reflected, as I will demonstrate later, even in how we write policy - by effectively writing ourselves out of that space too.

\section{Human spaces and places}

Marc Augé referred to 'space' as a more abstract concept than 'place'. 'Place' refers to an event (which has taken place), whilst we may discuss space in terms of 'the space of a week' (Augé, 1995). Augé brings to our attention the notion of 'non-places', which are still meaningful spaces in modernity, but are more like transit points (Augé, 1995). The examples of non-places we encounter in modern life are endless because they are constantly reconstituted (hotel chains, airport lounges, retail outlets and wireless networks are but a few). Yet these are not necessarily recontextualised to help us retain connections with things that have gone before. History has no place here and neutrality, not familiarity, is encouraged. Below I draw some parallels with these non-places, as I find in policy language a similar neutrality. Humans are not encouraged to be present in these texts as they bring baggage with them. They take up space, ask questions, refer to history and context, they cause congestion within documents, slowing down the slick processes achieved by technology. Even in virtual reality people must keep moving. The website I favoured yesterday has already vanished, just like the shop on the high street I visited only last week. These analogies share a common factor: the spaces of a clock dial are dictating the lengths of time in which we get to dwell in any of our human spaces, or non-places. People cannot remain long, if space has gone, they must move on, and on, and on.

\section{Academic acceleration}

Returning now to acceleration in the workplace of academia, it is not only the rooms in our university buildings that have lost familiarity. Our educational systems and technologies, and even the staff who support these, change rapidly around us. Once we chatted with support staff to develop teaching activities with technologies, now we consult with 'enhancement' officers who have written into their very titles the 'time is money' philosophy that technology enhances learning. Consequently, we may struggle to find a sphere of resonance in our surroundings or systems. We are told the use of technology has enhanced our teaching and learning, but there is little time to explore this philosophically, when one enhancement strategy subsumes another before we have had time to read it (Hayes, 2014). During the 1990s hope and promise was evident in postmodern theories for educational technology, where 'deep subjects' and 'complexity' were explored. Instead of simply seeing educational 
technology as a study in how to improve teaching and learning, it was examined as an art form, as texts and media. The educational technologist was compared to a film, art or television critic and the history of this rich field of work was linked with semiotics and critical pedagogy (Yeaman et al., 1996). In the 1991 text Paradigms Regained, 26 scholars sought to link critical theories with the broad rubric of educational technology (Hlynka and Belland, 1991). Yet we seem to have filled any pauses in time we might now use to discuss these. As a consequence, these critical conversations seemed to lose all momentum. I question below how this came about and whether there are clues in the policy language written to direct our performance at greater speed in higher education. It seems that such documents may play their part too, as conspirators with the clock.

\section{Workflows continue without our physical presence}

Once papers took time to reach us by post and memos were physical scripts to ponder over. Our strategies in universities now move more quickly than ever before, bringing tasks for us to attend to, whether we are there or not to receive them. They dwell on web pages we have no time to locate and travel via email at a speed we cannot keep pace with. Not being physically seated in the workplace is no excuse not to respond, for the clock is always ticking. The policies of modern universities, supported by the affordances of information technologies, have set the clock to tick to the pace of 'emergency as rule' (Thrift, 2000). The emergency route of metrics and endless audits to measure efficiency is in turn skilful at concealing the many 'hidden injuries of neo-liberal academia' (Gill, 2009). Policy continually inflicts upon us contradictions in government business models for higher education, where inspirational individuals must manage overflowing workloads (Warner, 2014).

Gill describes academic exhaustion, stress, overload, anxiety and feelings of 'out-of-placeness', as affective embodied experiences that seem to be silenced in the public spaces of the academy (Gill, 2009). She refers to 'the requirement to do more with less', citing the regular memos that always require additional commitments (Gill, 2009). Yet, rarely do we count seriously among the conspirators who keep us running on an accelerated academic treadmill, the endless documents, the texts themselves, that sit innocently on shelves in academic offices, online, hyperlinked to others, occupying emails and of course, archived. Everything nowadays is archived, because of course we might need it. Endless photos, videos of every talk ever given, collections of teaching resources, which are of course reusable, so we must retain them. Few people have time though to stop and search for something they might reuse from these collections. Yet, collectively, these material things embody not only exhortations of 'exchange value', to achieve more in a shorter space of time via technology, but they narrowly structure within words our very approaches for doing so.

\section{Sleep represents a pause}

On reflection, this behaviour bears little resemblance to the rhythmic life of a natural being. The practice of 'sleep hacking', for example, has emerged with an associated industry of books and coaching, which aid people to manage their busy lives on just three to five hours sleep per night (Lambert, 2014). Such practices, alongside the use of 'smart drugs' (such as Ritalin and Modafinil sourced through the Internet), favoured as 'performance enhancers' to retain alertness and postpone tiredness, are used increasingly by university students and even amongst faculty staff (Beardsworth, 2013). Here we find technologies in the form of drugs 
and techniques supporting our enslavement to the clock, in attempts to extend our labour but does this extend, or limit, human capacity to effect change? Sleep is of course interesting to contemplate as 'an enclave outside the existing global order' (Crary, 2013: 137). As a form of release from acceleration it is a place where a future without capitalism might even be rehearsed. It is a form of time that leads us elsewhere than to the things we own, or are told we need and 'it affirms the necessity of postponement' in our lives of a waiting, of a pause (Crary, 2013: 139). These are reminders that are worth retaining when the pace of turnover now demanded from us in universities conspires against any form of resonance for learning more deeply through our technologies, even in the very place where learning traditionally has been conducted. Yet when something actually resonates with us, it is more than simply a frequency of messages: it strikes a chord to deepen our tacit engagement and input. This has a rhythm of its own and has little to do with the ticking of time or the spaces on a clock dial. It is different also from a rhythmic snoring or breathing we might fall into during sleep, because it enriches our understanding, as we become attuned to a concept, rather than simply tuned into the passing of time and movement through a non-place. Critical questions arise, and these may take us backwards in time, as well as forwards. Perhaps what we discover changes what has gone before, to break the linear direction of our accelerated lives. How we define our approach in university policy for educational technology can reveal the values we place in modern society on both technology and human learning, through a scrutiny of language. Whilst this is just one approach, it offers a concrete means to confront ideological expressions about the role of technological mechanisms in our lives (Fairclough, 2007; Graham, 2002; Hayes, 2015; Hayes and Bartholomew, 2015).

\section{Confronting textual tyrants through Critical Discourse Analysis}

In response to Rosa's first point, that our social acceleration simply maintains the status quo, I briefly refer to some of my findings from a recent CDA of educational technology policy texts (Hayes, 2015). I link these with theory from Marx concerning 'exchange value' (Marx, 1867). In so doing I argue that our slavish dependence on mechanical time should not be viewed in isolation from other aspects of higher education. We need to pay attention to all manner of social and material structures that (together) keep us from developing a deeper resonance with our tools for learning. In the United Kingdom (UK) educational technology policy documents (and, by extrapolation, perhaps more global ones too), there has been a concentrated focus on 'the use of technology' to provide a return on investment in recent decades. This approach repeatedly stresses that in exchange for an efficient use of technology, human learning will be enhanced (Hayes and Bartholomew, 2015).

In an analysis of 2.5 million words of UK government policy and university strategy texts written between 1997 and 2012, through corpus linguistics, I noticed repeated patterns that embodied a simple economic calculation: in exchange for the use of technology there will be enhanced forms of learning. Claims followed repeated patterns such as the following:

... the use of technology can increase accessibility and flexibility of learning

... the use of technology can improve recruitment and retention

... the use of technology can enhance their learning and teaching experiences

In each example statement is an expectation of a form of profit from 'the use of technology'. It is afforded capability to increase, improve or enhance the particular learning-related topic 
at the end of each of these sentences. To explain the implications of this assumption further, technology, like any commodity, has 'value' which also represents a quantity of human labour. Marx (1867) distinguishes between 'use value' and 'exchange value'. 'Use value' relates to human social necessities, such as teaching or learning, that a technology might fulfil in conjunction with the human labour involved. On the other hand, 'exchange value' is a value that takes the human labour involved for granted, to realise a profit in an economic market. Policy discourse predicated on 'exchange value' provides a means for political economic agendas to make simplified claims in the name of technology, which can, according to Greener and Perriton (2005), distort the values (including the connections we make across time) of human learning communities. Development of educational technology has largely coincided with the development of neoliberal politics (and the marketisation of higher education) in advanced industrial countries (Jones, 2014). Whilst neo-liberal politics is not the main focus of this article, links are drawn with a narrow and dominant language about educational technology, as always providing an 'exchange value' for learning. However, to claim technology provides an exchange value is one thing, but to infer that technology actually performs our labour on our behalf, is quite another. In the following examples, as in those above, we see that again there are expectations of 'the use of technology'. Now, if we also pay attention to the verbs - to enhance, to address - we can notice that these actions, for example 'to address plagiarism' or 'to enhance learning and teaching', are literally performed by 'the use of technology' and no human person is credited.

... the use of technology to enhance learning and teaching

... the use of technology to address plagiarism

... the use of technology to enhance learning, teaching and assessment

... the use of technology to address the key challenges facing higher education

This was a common pattern in the large quantity of educational technology policy documents I analysed. Human agency was repeatedly delegated to objects (expressed as nouns) rather than to people. Below a similar pattern is replicated and it is the noun: 'this strategy' that 'aims' and 'strives', not the human who wrote it:

This strategy aims to accelerate the mainstreaming of technology-enhanced learning.

This strategy for e-learning strives to use e-learning to enhance the student learning experience.

Humans 'aim' and 'strive' for things, not technologies, booklets or websites. In policy, human acts of labour are thus severed textually from the academics who actually perform them. The connections are broken between us and our tools and techniques in the broadest sense because this form of writing leaves no space or time to imagine alternative forms of organisation. This has implications in terms of how we perceive technologies for learning, across time. There is not scope within this article to demonstrate in detail the specific linguistic analysis I undertook. For more on this particular methodology of corpus-based CDA applied to policy discourse please see Hayes (2015) and Hayes and Bartholomew (2015).

\section{The solids help to slow us down}

In the remainder of this article I consider why 'melting the solids' (Bauman, 2000) of human form within policy documents is problematic for learning through technology. I then explore how we might treat our emphasis on pressure from time rather differently in a networked learning context. Drawing on literature from STS supports an envisioning of technology as 
'posthuman' (Barad, 2003; Badmington, 2003), where people and technologies combine to form socio-technical systems in which material, 'solid' things matter. In an extreme neoliberal 'enframing' (Heidegger, 1977), people are locked in a state where they may become simply a resource, reified to serve as a means to an end. This approach becomes operationalised in language as people speak and write about humans as if they might be interchanged like objects, no different to any other items that might yield an exchange value. This means we lose sight of two important truths. Firstly, that humans do not have the capacity to work without rest like machines. People are vulnerable and need time, both to adjust to, and input into, change. Secondly, as creative beings, it is our relationship to objects, tools and social activities that confirm and even realise our individuality in learning situations, because 'man is affirmed in the objective world' (Marx, 1970; Matthewman, 2011: 170). To understand all objects as there to extract the maximum quantitative value in the shortest possible space of time is only to 'presence' them as a resource to set 'to work' (Heidegger, 1977; Richardson, 2012: 327). As people explain this in a framework of modern intentionality they lose something of their own identity (Richardson, 2012: 328). If we are to form a resistance to a seemingly untenable tempo in academic life and resist simply becoming 'liquid assets' as humans, we need to recall that we now live and work in times where 'the whole society is placed at the disposal of profit' (Negri, 1989: 79). This means confronting divisive, alienating practices that break our connections with both current and historical things, and with each other. This includes even reconsidering the ways in which we write and speak about the material world around us and the other humans within it. Taking time to consider what we write, and how we write it, is a powerful way to slow ourselves and others down. As a technology, the pen (and the digital devices we use to write) are powerful tools. Instead of writing:

This strategy for e-learning strives to use e-learning to enhance the student learning experience.

I might instead say:

As colleagues who teach in higher education, we are writing this strategy because we hope to bring new learning experiences to our diverse group of students.

What this second statement does is reintroduce a context that people can relate to. Readers of the first statement find themselves in a textual 'non-place'. Like the transit lounge of an airport there is little to identify with and we will all move swiftly on. Reading the second statement we may pause to ask ourselves if we fit into one of the groups mentioned, as a colleague or a student. We may notice a plurality that suggests there is room to be involved here, to take time to consider what is being written and what experiences it may lead to. Consequently, we might reflect on whether to input into this process where other humans are acknowledged, not evicted from the page.

\section{Speed is seductive}

Yet, even as confronting language can reveal to us another view on our process-driven lives, the question to consider next is just how much we really want to change our status quo. Douglas Kellner, in critical reflection on the work of Paul Virilio, discusses how new technologies provide a substitute reality, a virtual reality that becomes more powerful and seductive than ordinary reality (Kellner, 1999). Therefore, the acceleration we experience in virtual spaces, where we encounter instantaneous responses, fulfils something in us that 
responds to this. Perhaps this is a form of resonance too, but much faster than the human effort involved in more obvious forms of physical labour. Why then would we want to substitute this for a slower reality, where it takes time and effort to develop political solutions? Who needs a political revolution if you have a technological one (Runciman, 2014)? Over the last decade technology has proved it can be a loyal comrade in arms, with those who have sought to fight the system in a revolutionary wave of protests and civil wars across many borders that have become known as the Arab Spring (Howard et al., 2011). Social media, such as Twitter and Facebook, have spread democratic messages at a speed no parliaments can match. Although of course this same technology used to share ideas and tactics also tracks and records our movement and times our activities.

Perhaps increasingly difficult for people now trained for speed, is the prospect of trying to imagine a slower, yet still effective university that does not just produce endless policy, but actually allows humans time to read, critique and re-write that policy, to honestly reflect and account for human academic practice. The strange phenomenon of disappearing the references to humanity in policy about our labour with technology is yet another conspiratorial aspect of 'function creep' (Gregg, 2013), supporting the tyranny of the clock in our lives. Individuals are required to do more in less time, yet still they struggle to demonstrate what they have actually produced. This is little wonder if in strategies 'the use of technology' takes credit for their academic labour, but this also offers further scope for speed. After all if people are omitted, policy is simply describing efficient processes between 'things', as in any automated system. Politicians can accelerate the pace, through what is written on the page. Without humans as 'solids' clogging up the policy texts with questions, emotions and reflections, there are really no reasons not to be 'always on' (Gregg, 2013).

Statements that have lost their solid references to humans are now even less likely to urge the 'neoliberal academic subject: checking, monitoring, downloading' (Gill, 2009) to look up and notice that the sun is setting and the working day should be drawing to an end. Yet we ourselves contribute to liquidising our own labour, through 'presence bleed' (Gregg, 2013). No one forces us to turn on mobile devices to work around the clock and spill our labour into every space and non-place. There are unwritten expectations that we should try to keep up, yet not appear to be risking a good work-life balance in the process. Even the buzz of a new text or the audible ding of a new email arriving has its role to play in this form of self-control (or lack of it...) depending on how these habits are viewed. These sounds invite an instant response from us. Adrenaline flows on days we feel we have conquered the rush of text by sending forth our own rush of messages. We act as if we alone bear responsibility for a system that has become fragmented and accelerated beyond anyone's control. Perhaps it is fear that if we pause, we may learn something that significantly changes the tempo.

\section{Resonance}

Yet, turning the earth with a spade in your garden, perhaps you recall finding a more natural rhythm. Something starts to resonate with you, as you identify with a different kind of input and output of human activity that is not so attuned to the clock. Energy from your body is fed into the digging process and you notice a timing that is not the same as mechanical time, because you control it and refine it. Humans simulate this motion constantly in gyms, but usually as a timed performance on treadmills (with clocks), and so still these physical activities are squeezed into pockets of automated life. How might it be otherwise? Are we 
somehow missing another perspective on what we currently do that might allow our labour and learning through technology to resonate more deeply with us?

Firstly, I would argue that we do need to bring the 'solids' back. This means actively writing ourselves and our human presence and labour back into policy. We need to reoccupy the language...before we are gone from it altogether (Hayes and Bartholomew, 2015). This would be one way to begin to account for our liquid labour that becomes lost in the calculation of economic exchange value. To slow the flow of unrecognised effort, we need to firmly acknowledge in our strategy texts a resonance between humanity and technology that is not concerned with profit alone. It concerns our co-existence with our tools and our mutual constitution by them (Mackenzie and Wajcman, 1999).

\section{A commitment to 'be there' in the policy}

Still though, we have the problem of time urging us to move ever faster towards the future. We need now to make time for critical thought about why our academic work, supported by technology, seems to take our time away, instead of liberating us. People who are consumed by the fear of never 'catching up' cannot contribute to political change because this takes time, and they simply do not have it. Yet if academics do not take time to resist injustice and input into policy to seek reform, they cannot be surprised if their students accept the status quo. Runciman argues that technology has the power to make politics seem obsolete (Runciman, 2014). Unfortunately superficial political engagements are not enough to work towards lasting changes. If people only peddle faster to maintain the status quo (Rosa, 2013), this may turn out to be a very superficial reality. Therefore, we need to ask if the status quo we seek to maintain in higher education is now simply another nonplace (Augé, 1995). If so, what really needs to change is for the academy to recall its own history and in so doing, question our current reality, and indeed re-assess our hopedfor futures.

\section{Beyond the tyranny of time}

Mark Currie (2007) provides us with three notions of the contemporary that can help to expand our thinking beyond ideas that the tyranny of time and acceptance of social acceleration are inevitable. These are helpful concepts to apply to digital media to take us beyond a simple slavery to time, and resonate more deeply to build connections with philosophy. These are time-space compression, accelerated recontextualisation and archive fever. Through these ideas we can open new discussions about how we actually experience the present in networked learning situations. Although we may write policy discourse in sentences of orderly significance, making claims about things 'the use of technology' has achieved, a much more chaotic co-presence of meanings is all around us (Currie, 2007).

The first point about time-space compression was mentioned at the start. Space and time are now represented differently through, for example, fast telecommunications and the speed of jet travel. We experience a simultaneity of being able to move across spaces yet communicate in different time zones. The result is a form of 'contaminated present', through the collapse of temporal distance (Currie, 2007).

The second concept of recontextualisation is a model where the present is understood as 'the bearer of historical traces' (Currie, 2007). We now experience very rapid forms of accelerated recontextualisation, due to technologies that close the gap between original 
styles, for example, and newer versions that are recontextualised. The present both anticipates its own past and is experienced, like everything else in the contemporary world, as the object of a future memory. 'The process which consigns the present to memory is conducted at infinite speed, since the present commodity is always already in the past' (Currie, 2007: 11).

This links to the last concept discussed by Currie of archive fever, where the present is lived as if it were the object of a future memory. Derrida described this as a 'future orientation', a mode of anticipation that structures the present. In our highly developed capitalist society, rather than an event being recorded because it happens, the event happens because it is recorded. I record a 'selfie' (a snapshot of myself) in anticipation of its future action, as something that will make a good story.

What these examples do is help to free our thoughts from the debilitating belief that the tyranny of time is inevitable and that we are enslaved to it. This is therefore a call for others to pick up this discussion and see where it takes us in the field of educational technology research for networked learning. We should though remain aware of who, and what, conspires with time in different structural forms to direct (and take credit for) our labour in modern capitalist society. Technology has in a sense enabled us to 'converse' with both the past as a drama, and future acts that may undo what has gone before. With such knowledge we can wonder at why we would write policy for educational technology as if ordered processes take place in linear patterns of time. This only serves to sever connections (over time) with people and all manner of 'things', for communicating in ways that support one another's learning. At the very least it raises questions about how we might revisit the writing of strategy for educational technology.

Let us begin to collectively write the people back in and along with restoring humanity to these pages, bring compassion and understanding to heal the 'hidden injuries' in neoliberal academia (Gill, 2009). Perhaps at the same time we can reconsider how we support our students in the non-places of our universities. This is necessary work when many students see no reason to engage with politics, and technology has taken the place of democratic process. Universities are now non-places that simply act like transit points and are constantly reconstituted within capitalism. We must ensure they are recontextualised too and not severed from their historical role. Non-places need not be negative, but they should prompt us to ask: what is the mode of anticipation that structures 'the present' for academia? Dare we yet hope it could lead to a sphere of resonance for networked learning?

\section{Funding}

This research received no specific grant from any funding agency in the public, commercial or not-forprofit sectors.

\section{References}

Augé M (1995) Non-places: Introduction to an Anthology of Modernity. London: Verso.

Badmington N (2003) Theorizing posthumanism. Cultural Critique 53(1): 10-27.

Barad K (2003) Posthumanist performativity: Towards an understanding of how matter comes to matter. Signs: Journal of Women in Culture and Society 28(3): 801-831.

Bauman Z (2000) Liquid Modernity. Cambridge: Polity Press.

Bayne S (2015) What's the matter with 'technology-enhanced learning'? Learning Media and Technology 40(1): 5-20. 
Beardsworth T (2013) A quarter of my friends use them. Evening Standard. Available at: http:// www.standard.co.uk/lifestyle/esmagazine/a-quarter-of-my-friends-use-themthe-oxbridge-studentsaddicted-to-brainboosting-smart-drugs-8901879.html (accessed 29 October 2014).

Cohen R and Kennedy P (2013) Global Sociology, 3rd ed. New York: Palgrave Macmillan.

Crary J (2013). 24/7: Late Capitalism and the Ends of Sleep. London: Verso.

Currie M (2007) About Time: Narrative, Fiction and the Philosophy of Time. Edinburgh: Edinburgh University Press.

Davis M (1990) City of Quartz: Excavating the Future in LA. London: Vintage.

Fairclough N (2007) Global capitalism and change in higher education: Dialectics of language and practice, technology, ideology. In: BAAL conference, Edinburgh.

Gill R (2009) Breaking the silence: The hidden injuries of neo-liberal academia. Secrecy and Silence in the Research Process: Feminist Reflections. London: Routledge.

Graham P (2002) Hypercapitalism: A political economy of informational idealism. New Media and Society 2(2): 131-156.

Greener I and Perriton L (2005) The political economy of networked learning communities in higher education. Studies in Higher Education 30(1): 67-79.

Gregg M (2013) Work's Intimacy. London: John Wiley \& Sons.

Hayes S (2014) Learning from a deceptively spacious policy discourse. In: proceedings of the networked learning 2014 conference, Edinburgh, UK, 7-9 April 2014. Available at: http://www.networkedlearningconference.org.uk/abstracts/pdf/hayes.pdf (accessed 28 October 2014).

Hayes S (2015) Counting on technology to enhance learning. In: Jandrić P and Boras D (eds) Education and the Network: A Critical Encounter. London: Springer.

Hayes S and Bartholomew P (forthcoming, 2015) 'Where's the humanity? Challenging the policy discourse of technology enhanced learning. In: Technology Enhanced Learning in Higher Education. London: Libri.

Heidegger M (1977) The Question Concerning Technology and Other Essays. New York, London: Garland Publishing, Inc.

Hlynka D and Belland JC (eds) (1991) Paradigms Regained: The Uses of Illuminative, Semiotic, and Post-modern Criticism as Modes of Inquiry in Educational Technology: A Book of Readings. Englewood Cliffs, New Jersey: Educational Technology Publications.

Howard PN, Duffy A, Freelon D, et al. (2011) Opening closed regimes: What was the role of social media during the Arab Spring? Seattle: University of Washington, Project on Information Technology and Political Islam.

Jameson F (1992) Postmodernism and consumer society. In: Brooker P (ed.) Modernism/ Postmodernism. London, New York: Longman.

Jones C (2014) The politics of networked learning in an age of austerity. In: proceedings of the networked learning 2014 conference, Edinburgh, UK, 7-9 April 2014. Available at: http://www.networkedlearningconference.org.uk/abstracts/pdf/jones.pdf $\quad$ (accessed 10 September).

Jones C and Steeples C (2002) Perspectives and issues in networked learning. In: Jones C and Steeples C (eds) Networked Learning: Perspectives and Issues. London: Springer, pp. 1-14.

Kellner D (1999) Virilio, war and technology some critical reflections. Theory, Culture \& Society 16(56): 103-125.

Lambert C (2014) It's called sleep hacking. The Guardian. Available at: http://www.dailymail.co.uk/ femail/article-2632090/Its-called-sleep-hacking-new-trend-fro-training-mind-body-cope-far-sleepSo-doctors-worried-woman-busy-sleep-FOUR-hours-night.html (accessed 4 September 2014).

MacKenzie D and Wajcman J (1999) The Social Shaping of Technology. Milton Keynes: Open University Press.

Marcuse H (1964) One-dimensional Man. Boston: Beacon Press.

Marx K (1970) The Economic and Philosophic Manuscripts of 1844 and the Communist Manifesto. London: Lawrence \& Wishart. 
Marx K (1867) Capital, a critique of political economy. Available at: http://www.marxists.org/archive/ marx/works/download/pdf/Capital-Volume-I.pdf (accessed 20 September 2014).

Matthewman S (2011) Technology and Social Theory. New York: Palgrave.

Negri T (1989) The Politics of Subversion: A Manifesto for the 21st Century. Cambridge: Polity Press.

Richardson J (2012) Heidegger. London: Routledge.

Rosa H (2013) Social Acceleration: A New Theory of Modernity. New York: Columbia University Press.

Runciman D (2014) Politics: Ideas in Profile. London: Profile Books.

Thrift N (2000) Performing cultures in the new economy. Annals of the Association of American Geographers 90(4): 674-692.

Turkle S (2011) Alone Together: Why We Expect More from Technology and Less from Each Other. New York: Basic Books.

Warner M (2014) Diary: why I quit. London Review of Books 36(17): 42-43.

Wellman B (2001) Physical place and cyberplace: The rise of personalized networking. International Journal of Urban and Regional Research 25(2): 227-252.

Winner L (1993) Artifacts/ideas and political culture. In: Teich A (ed.) Technology and the Future, 6th ed. New York: St Martin's Press.

Woodcock G (1944) The Tyranny of the Clock. London: Wooden Shoe Books.

Yeaman A, Hlynka D, Anderson J, et al. (1996) Postmodern and poststructuralist theory. In: Jonassen D (ed.) Handbook of Research for Educational Communications and Technology. New York: Simon and Shuster Macmillan, pp.226-252.

\section{Author biography}

Sarah Hayes is a Lecturer in Technology Enhanced and Flexible Learning in the Centre for Learning, Innovation and Professional Practice, Aston University. Sarah teaches on the PG Cert for higher education, PG Dip and MEd, having previously taught modules in Sociology of Technology and Understanding Popular Culture. Sarah's research interests include the role of policy language in structuring links between technology and learning in higher education. She would like to further the debate on deceleration of academic life and writing policy in universities that is more closely informed by social practice, to openly declare the human labour involved. 